Ministry of Defense Military Technical College

Kobry Elkobbah, Cairo, Egypt

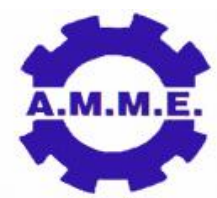

AMME-14 $14^{\text {th }}$ International Conference on Applied Mechanics and Mechanical Engineering

May, 25 - 27, 2010

\title{
TA-1
}

\section{Preparation and Characterization of Mullite Fiber \\ Reinforced Alumina Matrix.}

\author{
Prof. Dr. Salma Naga \\ National Research Center
}

\begin{abstract}
:
In the present study we succeeded in the preparation of short ceramic fiber reinforced alumina matrix composites which posses properties not tailored by alumina matrix. The composites were fabricated by mechanical mixing of $0,5,10,15$, and 20 wt\% home - made mullite fibers having different aspect ratios with $95,90,85$ and $80 \mathrm{wt} \%$ alumina matrix powder.

The specimens were sintered at temperatures between $1500^{\circ} \mathrm{C}$ and $1650^{\circ} \mathrm{C}$. The ceramic matrix composites were characterized by determining their physical properties in terms of bulk density and apparent porosity as well as, their phase composition using $X$-ray diffraction analysis. SEM examination and mechanical measurement preformed on only high density samples from each size fraction and fiber content. It was found that the properties of the prepared composites depended on the fiber content, the fiber/matrix interface and the fiber diameter. XRD analysis of the composites indicates that the fibers did not suffer degradation even when they were fired at elevated temperatures.

The study showed that it is possible to control the properties of the short oxide fiber reinforced - alumina matrix composite by controlling the content and diameter of the oxide fibers. Under such condition s it is easy to tailor the properties to a specific application.
\end{abstract}

